Article

\title{
Effects of Red Ginseng Extract on the Pharmacokinetics and Elimination of Methotrexate via Mrp2 Regulation
}

\author{
Sowon Lee ${ }^{1}$, Mihwa Kwon ${ }^{1}$, Min-Koo Choi ${ }^{2, *}$ and Im-Sook Song ${ }^{1, *(1)}$ \\ 1 College of Pharmacy and Research Institute of Pharmaceutical Sciences, Kyungpook National University, \\ Daegu 41566, Korea; okjin917@hanmail.net (S.L.); mihwa_k@naver.com (M.K.) \\ 2 College of Pharmacy, Dankook University, Cheon-an 31116, Korea \\ * Correspondence: minkoochoi@dankook.ac.kr (M.-K.C.); isssong@knu.ac.kr (I.-S.S.); \\ Tel.: +8241-550-1438 (M.-K.C.); +8253-950-8575 (I.-S.S.)
}

Academic Editor: Thomas Efferth

Received: 22 October 2018; Accepted: 8 November 2018; Published: 12 November 2018

\begin{abstract}
We aimed to investigate the effects of red ginseng extract (RGE) on the expression of efflux transporters and to study the pharmacokinetics of representative substrate. For this, rats received single or repeated administration of RGE $(1.5 \mathrm{~g} / \mathrm{kg} /$ day $)$ for 1 and 2 weeks via oral gavage. mRNA and protein levels of multidrug resistance-associated protein2 (Mrp2), bile salt export pump (Bsep), and P-glycoprotein (P-gp) in the rat liver were measured via real-time polymerase chain reaction and Western blot analysis. Ginsenosides concentrations from the rat plasma were also monitored using a liquid chromatography-tandem mass spectrometry (LC-MS/MS) system. Plasma concentrations of ginsenoside $\mathrm{Rb} 1, \mathrm{Rb} 2$, Rc, and $\mathrm{Rd}$ following repeated administration of RGE for 1 and 2 weeks were comparable but significantly higher than those after single administration of RGE. These dosing regimens did not induce significant biochemical abnormalities in the liver, kidneys, and lipid homeostasis. In the RGE repeated oral administration groups, the mRNA and protein levels of Mrp2 significantly decreased. Accordingly, we investigated the changes in the pharmacokinetics of methotrexate, a probe substrate for Mrp2, following intravenous administration of $3 \mathrm{mg} / \mathrm{kg}$ methotrexate to rats in the RGE 1-week repeated oral administration group, compared to that in the control group. Biliary excretion, but not urinary excretion, of methotrexate decreased in the RGE repeated administration group, compared to that in the control group. Consequently, the plasma concentrations of methotrexate slightly increased in the RGE repeated administration group. In conclusion, repeated administration of RGE for 1 week resulted in a decrease in Mrp2 expression without inducing significant liver or kidney damage. Pharmacokinetic herb-drug interaction between RGE and methotrexate might occur owing to the decrease in the mRNA and protein levels of Mrp2.
\end{abstract}

Keywords: red ginseng extract (RGE); multidrug resistance-associated protein 2 (Mrp2); pharmacokinetics; methotrexate

\section{Introduction}

Ginseng (the roots and rhizomes of Panax ginseng C.A. Meyer) has been extensively used for more than 2000 years in East Asian countries [1,2]. Red ginseng extract (RGE) is produced from 6-year-old fresh ginseng by steaming and drying, which leads to biochemical transformation of various ginsenosides [3]. Ginsenosides are considered the major active pharmacological constituents of ginseng. They have been shown to exhibit anti-neoplastic, anti-hypertensive, anti-diabetic, anti-inflammatory, anti-oxidant, anti-allergic, neuroprotective, and immunological effects [4-7]. 
Similar to other herbal medicines, ginseng products are frequently co-administered with prescribed Western medications. Accordingly, the potential for pharmacokinetic herb-drug interactions between ginseng and concomitantly administered drugs should be evaluated since they may result in toxicity or treatment failure [8]. Ginseng could alter the activity of cytochrome P450 (CYP) enzymes, the most important drug-metabolizing enzymes, which can affect the pharmacokinetics and efficacy of the co-administered drug. Administration of Panax ginseng for 4 weeks $(1.5 \mathrm{~g} /$ day) resulted in slight inhibition of CYP2D6 activity, with no significant effects on CYP3A4, CYP1A2, and CYP2E1 in elderly subjects [9]. Two-week red ginseng treatment $(10 \mathrm{~mL}$ of concentrated red ginseng extracts, dried ginseng 64\%) weakly inhibited CYP2C9, CYP2D6, and CYP 3A4 activity, whereas it weakly induced CYP2D6 activity [10].

Besides inhibition or induction of CYP, the modulation of drug-transporters is also an important mechanism for herb-drug interaction [11-13]. Drug efflux transporters such as multidrug resistance-associated protein (Mrp), bile salt export pump (Bsep), and P-glycoprotein (P-gp) play important roles in the efflux of their substrates from the cells, thereby protecting the cells against these high concentrations of substrates, reducing intestinal absorption, or facilitating excretion of the substrate drugs [14]. Moreover, alteration of efflux transporter activity or expression could affect the tissue distribution, systemic disposition, and intestinal absorption of substrate drugs, thereby affecting their efficacy $[15,16]$. Despite the growing understanding of the role of the transport system in the pharmacokinetics, drug response, and herb-drug interactions, the effects of red ginseng on the efflux transporters have not yet been fully elucidated. A clinical study reported that red ginseng exhibited limited effects on P-gp function following 2-weeks repeated administration of red ginseng product in humans [10].

Therefore, in the present study, we investigated the effects of single or repeated administration of RGE on efflux transporters and examined the potential changes in the pharmacokinetics of their substrate drugs. Of these, Mrp2 drew our interest because it is mainly involved in the pharmacokinetics and renal and biliary elimination of its substrate anions as well as amphipathic drugs that conjugate with glucuronide, sulfate, and glutathione (GSH) $[17,18]$. For example, numerous anionic drugs such as methotrexate, SN38, cisplatin, vinblastine, and sulfinpyrazone are mainly eliminated from the body by Mrp2 $[19,20]$. GSH facilitates the biliary excretion of amphipathic drugs via Mrp2 through the conjugation reaction and also acts as a regulator of redox homeostasis [21]. RGE has been shown to be effective in reducing oxidative stress through the Nrf2 signaling pathway [7,22]. Nrf2 is a transcriptional factor that regulates Mrp2 expression [21], suggesting herb-drug interaction between red ginseng and Mrp2 substrates.

\section{Results}

\subsection{Concentration of Ginsenosides in Red Ginseng Extracts and Rat Plasma}

To measure ginsenoside concentrations, we developed analytical methods for quantification of 14 ginsenosides in diluted RGE and rat plasma samples with slight modification of a previously described method [23]. Among the 14 ginsenosides tested, eight ginsenosides (Rb1, Rb2, Rc, Rd, Rg3, $\mathrm{Re}, \mathrm{Rh} 1$, and Rg1) could be quantitated in the diluted RGE. Peaks of the other six ginsenosides (Rh2, F2, compound K, protopanaxadiol, F1, and protopanaxatriol) were not detected since these ginsenosides are minor components and are biological metabolites of $\mathrm{Rb} 1, \mathrm{Rb} 2, \mathrm{Re}$, or $\mathrm{Rg} 1$ that could be produced via metabolism in the gut microflora [24,25]. The contents of ginsenosides could differ depending on the preparation procedure for RGE (steaming and drying conditions); however, the contents of major ginsenosides, such as $\mathrm{Rb} 1, \mathrm{Rb} 2, \mathrm{Rc}$, and $\mathrm{Rg} 3$, were comparable to previously reported values [26,27]. Ginsenoside contents in RGE used in this study are summarized in Table 1 . Rb1 content was the highest $(0.19 \%)$, and $\mathrm{Rb} 2, \mathrm{Rc}$, and $\mathrm{Rg} 3$ contents were $0.09 \%, 0.1 \%$, and $0.13 \%$, respectively. $\mathrm{Rd}, \mathrm{Re}$, and Rh1 contents in RGE were in the range of $0.05-0.06 \%$. 
Table 1. Contents of ginsenosides in RGE.

\begin{tabular}{ccc}
\hline Ginsenoside & & ( $\mu$ g Ginsenoside/g RGE) \\
\hline & $\mathrm{Rb} 1$ & $1925 \pm 38.3$ \\
& $\mathrm{Rb} 2$ & $929.6 \pm 32.0$ \\
& $\mathrm{Rc}$ & $1015 \pm 32.4$ \\
& $\mathrm{Rd}$ & $541.6 \pm 47.0$ \\
& $\mathrm{Rh} 2$ & $\mathrm{ND}$ \\
& $\mathrm{Rg} 3$ & $1291 \pm 47.5$ \\
& $\mathrm{~F} 2$ & $\mathrm{ND}$ \\
& Compound K & $\mathrm{ND}$ \\
& Protopanaxadiol & $\mathrm{ND}$ \\
\hline \multirow{2}{*}{ 20(s)-protopanaxatriol } & $\mathrm{Re}$ & $532.1 \pm 36.3$ \\
& $\mathrm{Rh} 1$ & $654.2 \pm 31.2$ \\
& $\mathrm{Rg} 1$ & $160.0 \pm 0.4$ \\
& F1 & $\mathrm{ND}$ \\
& Protopanaxatriol & $\mathrm{ND}$
\end{tabular}

Data are expressed as mean \pm SD from triplicated measurements of ginsenosides in RGE. ND: Not detected. RGE: Red ginseng extract.

After RGE was orally administered to rats at single or multiple doses for 1 or 2 weeks, the plasma concentrations of ginsenosides were also monitored. Among the 14 ginsenosides monitored, only four ginsenosides ( $\mathrm{Rb} 1, \mathrm{Rb} 2, \mathrm{Rc}$, and $\mathrm{Rd}$ ) could be quantitated (Table 2); however, the other 10 ginsenoside peaks were not detected in rat plasma. The representative multiple reaction monitoring (MRM) chromatograms for the four identified ginsenosides ( $\mathrm{Rb} 1, \mathrm{Rb} 2, \mathrm{Rc}$, and $\mathrm{Rd}$ ) and five unidentified ginsenosides (Rg3, compound K, Re, Rh1, and Rg1) are shown in Figure 1. Plasma concentrations of ginsenosides $\mathrm{Rb} 1, \mathrm{Rb} 2$, and $\mathrm{Rc}$ following single oral administration (SA) of RGE were comparable to each other and greater than the plasma concentrations of Rd (Table 2). Repeated administration of RGE for 1 week (1WRA) resulted in an increase in plasma ginsenoside concentrations, compared to those in the SA group; however, they were not significantly different from those in the 2WRA group (Table 2). The results suggested that ginsenosides accumulated in the plasma because of their long elimination half-life $\left(\mathrm{t}_{1 / 2}\right)$. For example, $\mathrm{Rb} 1$ is the most abundant and stable ginsenoside with a long elimination half-life of $58.47 \mathrm{~h}[28,29]$. The results also suggested that the steady-state plasma concentrations were reached within 1 week and maintained up to 2 weeks. Although the steady-state plasma concentrations of ginsenosides did not match with the order of ginsenoside contents in RGE (Tables 1 and 2), the major components in RGE ( $\mathrm{Rb} 1, \mathrm{Rb} 2$, and $\mathrm{Rc}$ ) existed in the rat plasma at the highest concentration levels. Thus, it was suggested that $\mathrm{Rb} 1, \mathrm{Rb} 2$, and Rc could permeate the intestinal membrane despite their hydrophilicity and large molecular size based on their multiple glycoside conjugation $[3,30]$.

Table 2. Plasma concentration of ginsenosides in rat plasma $2 \mathrm{~h}$ after the last oral administration of RGE at a dose of $1.5 \mathrm{~g} / \mathrm{kg} /$ day.

\begin{tabular}{lcccc}
\hline \multirow{2}{*}{ Ginsenoside } & & \multicolumn{3}{c}{ Plasma Concentration (ng/mL) } \\
\cline { 3 - 5 } & & SA (1.5 g/kg/day) & $\begin{array}{c}\text { 1WRA (1.5 g/kg/day } \\
\text { for 1 week) }\end{array}$ & $\begin{array}{c}\text { 2WRA (1.5 g/kg/day } \\
\text { for 2 weeks) }\end{array}$ \\
\hline & $\mathrm{Rb} 1$ & $8.9 \pm 2.3$ & $33.6 \pm 10.1^{*}$ & $32.1 \pm 12.4^{*}$ \\
$\mathrm{Rb} 2$ & $7.2 \pm 1.6$ & $25.1 \pm 6.4^{*}$ & $22.3 \pm 7.8^{*}$ \\
$\mathrm{Rc}$ & $6.1 \pm 1.6$ & $25.5 \pm 7.9^{*}$ & $25.1 \pm 8.5^{*}$ \\
20(s)-protopanaxadiol & $\mathrm{Rd}$ & $1.8 \pm 0.6$ & $9.8 \pm 2.5^{*}$ & $11.5 \pm 4.5^{*}$ \\
& $\mathrm{Rh} 2$ & $\mathrm{ND}$ & $\mathrm{ND}$ & $\mathrm{ND}$ \\
& $\mathrm{Rg}$ & $\mathrm{ND}$ & $\mathrm{ND}$ & $\mathrm{ND}$ \\
& $\mathrm{F} 2$ & $\mathrm{ND}$ & $\mathrm{ND}$ & $\mathrm{ND}$ \\
& Compound K & $\mathrm{ND}$ & $\mathrm{ND}$ & $\mathrm{ND}$ \\
& Protopanaxadiol & $\mathrm{ND}$ & $\mathrm{ND}$ & $\mathrm{ND}$ \\
\hline
\end{tabular}


Table 2. Cont

\begin{tabular}{lcccc}
\hline \multirow{2}{*}{ Ginsenoside } & & \multicolumn{3}{c}{ Plasma Concentration (ng/mL) } \\
\cline { 3 - 5 } & & SA (1.5 g/kg/day) & $\begin{array}{c}\text { 1WRA (1.5 g/kg/day } \\
\text { for 1 week) }\end{array}$ & $\begin{array}{c}\text { 2WRA (1.5 g/kg/day } \\
\text { for 2 weeks) }\end{array}$ \\
\hline \multirow{3}{*}{ 20(s)-protopanaxatriol } & $\mathrm{Re}$ & $\mathrm{ND}$ & $\mathrm{ND}$ & $\mathrm{ND}$ \\
& $\mathrm{Rh} 1$ & $\mathrm{ND}$ & $\mathrm{ND}$ & $\mathrm{ND}$ \\
& $\mathrm{Rg} 1$ & $\mathrm{ND}$ & $\mathrm{ND}$ & $\mathrm{ND}$ \\
& $\mathrm{F} 1$ & $\mathrm{ND}$ & $\mathrm{ND}$ & $\mathrm{ND}$ \\
& Protopanaxatriol & $\mathrm{ND}$ & $\mathrm{ND}$ & $\mathrm{ND}$ \\
\hline
\end{tabular}

Data are expressed as mean \pm SD from four rats of control, SA, 1WRA, and 2WRA groups. ${ }^{*} p<0.05$, significant compared with SA group by Student's $t$-test. ND: Not detected. RGE: red ginseng extract.

(A) Blank plasma
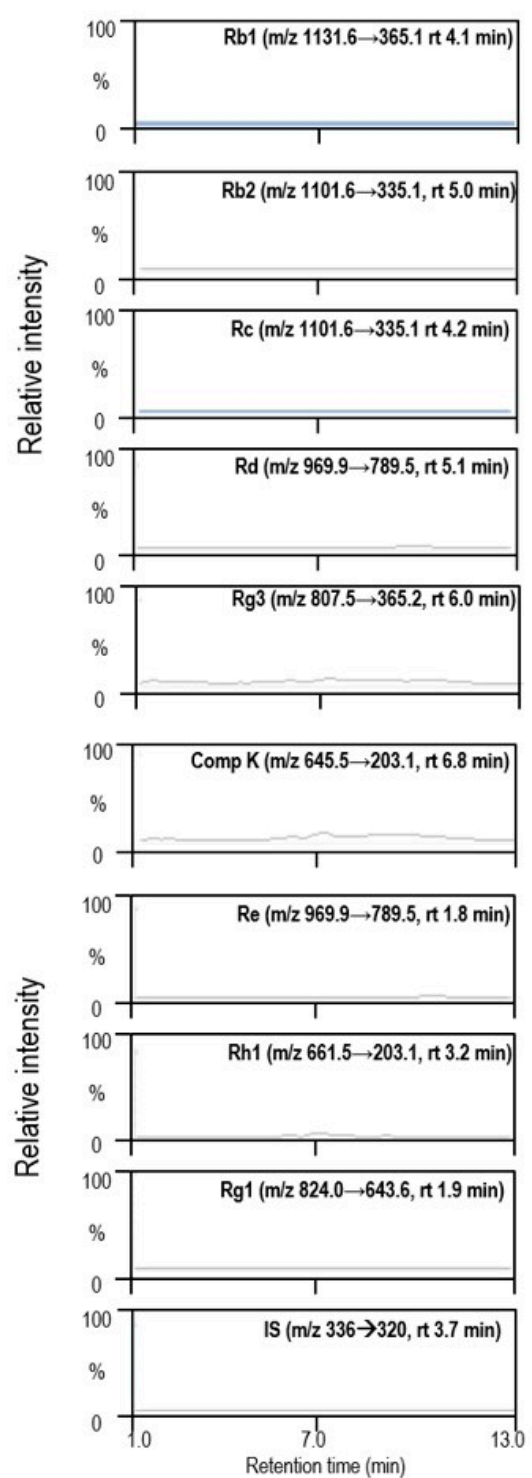

(B) Spiked plasma
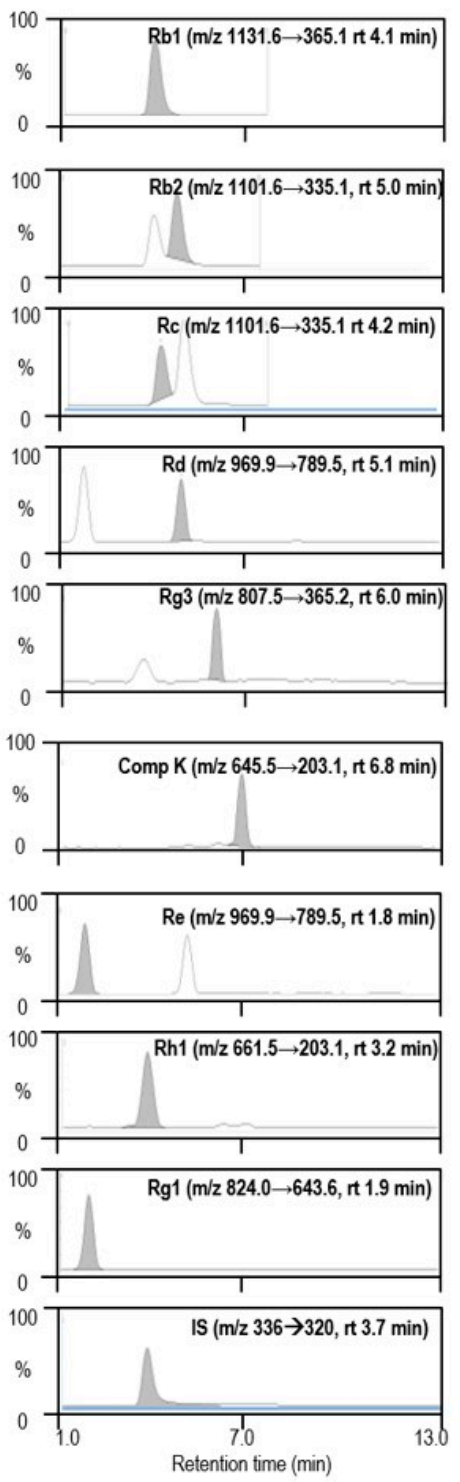

(C) Plasma samples
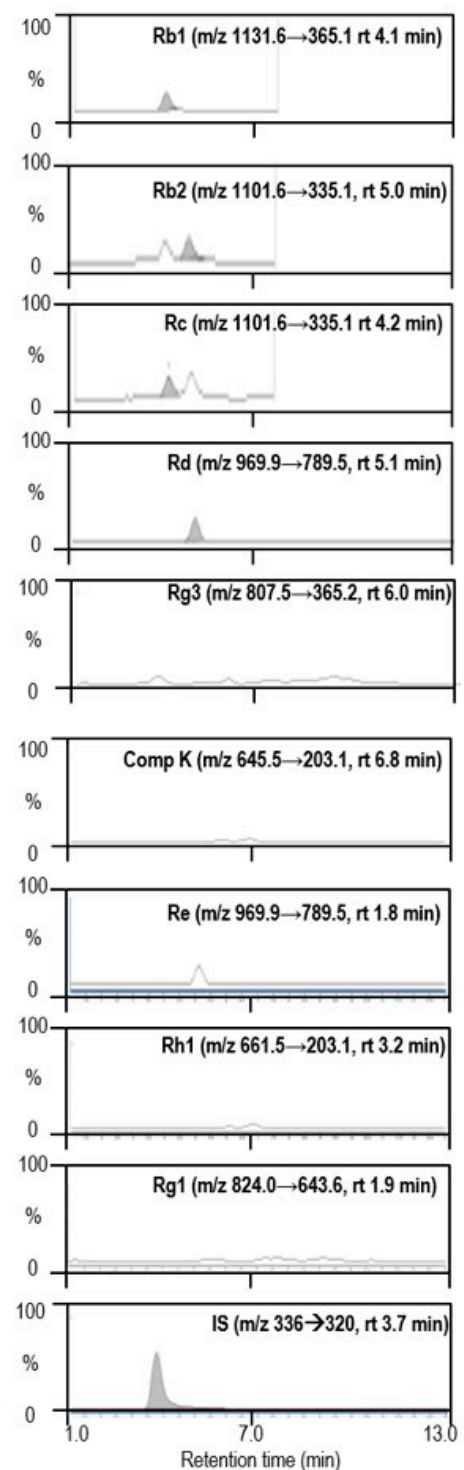

Figure 1. Representative multiple reaction monitoring (MRM) chromatograms of ginsenosides $\mathrm{Rb} 1$, $\mathrm{Rb} 2, \mathrm{Rc}, \mathrm{Rd}, \mathrm{Rg} 3$, compound K (Comp K), Re, Rh1, Rg1, and berberine (internal standard, IS) in (A) rat blank plasma, (B) standard ginsenosides $(20 \mathrm{ng} / \mathrm{mL})$ spiked in rat blank plasma, and (C) plasma samples following single oral administration of RGE $(1.5 \mathrm{~g} / \mathrm{kg})$. 


\subsection{Analysis of the mRNA Expression of Efflux Transporters}

Because of the potential of drug interactions between herbal medicines and efflux transporters, we measured the mRNA expression of efflux transporters, such as Bsep, P-gp, Mrp1, and Mrp2 in the liver tissues from rats in the control, SA, 1WRA, and 2WRA groups (Figure 2). The expression of P-gp, and Bsep did not change; however, Mrp1 expression slightly decreased in both single- and multiple-dose RGE-treated groups although it did not reach statistical significance. Mrp2 expression slightly decreased in the SA group but significantly decreased in the repeated-dose RGE-treated groups. There was no significant difference in Mrp2 expression between the 1WRA and 2WRA groups. Based on the plasma ginsenoside concentrations and mRNA expression level, further comparison studies were performed among the control, SA, and 1WRA groups.

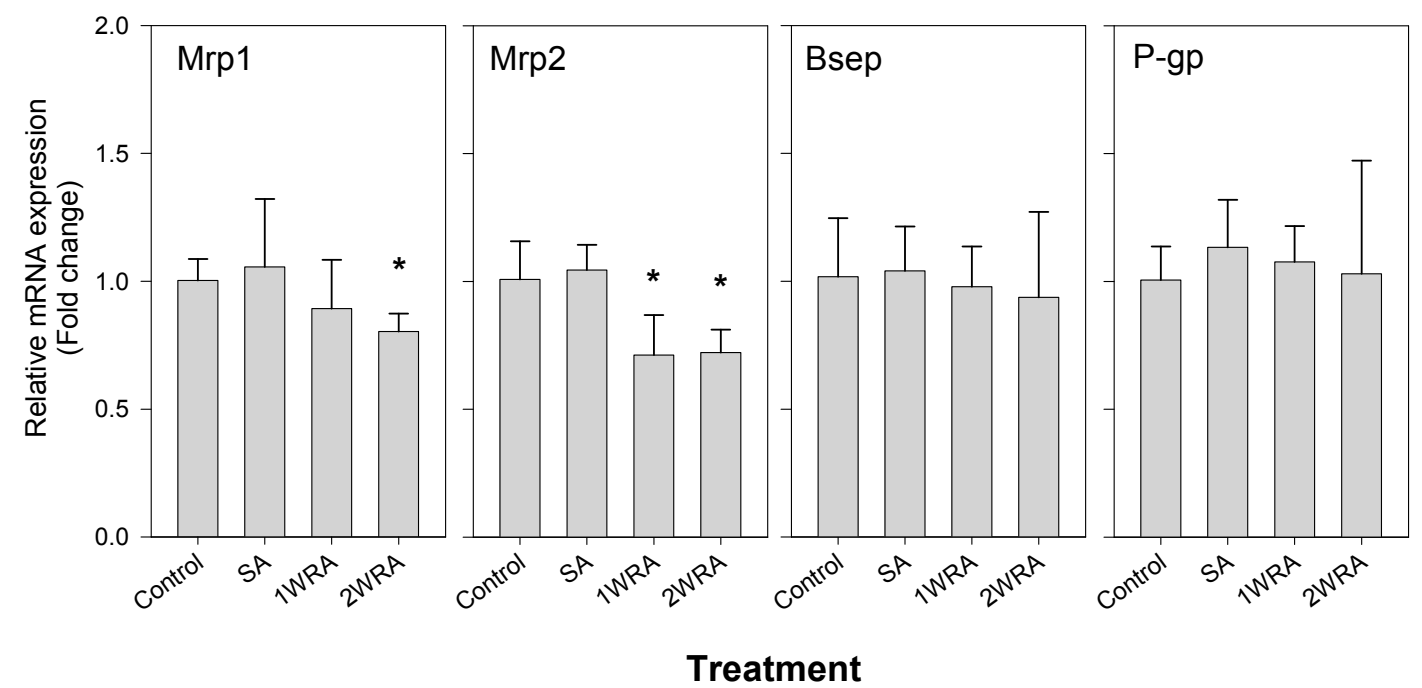

Figure 2. mRNA expression level of multidrug resistance-associated protein 1 (Mrp1), Mrp2, bile salt export pump (Bsep), and P-glycoprotein (P-gp) in the liver of rats in the control, single administration (SA), and repeated administration of RGE (1.5 g/ kg, PO) for 7 days (1WRA) and 14 days (2WRA) groups. Hrpt1 was used as an internal standard. Each bar represents the mean \pm SD from four rats per group. ${ }^{*} p<0.05$, significant compared with SA group by Student's $t$-test.

\subsection{Western Blot Analysis of Mrp2}

To confirm the decrease in the mRNA expression of Mrp2 in the repeated-dose RGE-treated groups, Western blot analysis was performed using the liver tissues collected from rats in the control, SA, and 1WRA groups. As shown in Figure 3, Mrp2 protein levels significantly decreased in the liver tissues of rats in the 1WRA group, compared to that in the control group.

\subsection{Effect of RGE Treatment on Biochemical Parameters for Liver and Renal Function}

The levels of alanine aminotransferase (ALT) and aspartate aminotransferase (AST) were not significantly affected by multiple-dose administration of RGE (1.5 g/ kg/day), suggesting that it had negligible effects on liver function (Table 3). Additionally, no changes were observed in the levels of triglycerides, total cholesterol, high-density lipoprotein (HDL) cholesterol, low-density lipoprotein (LDL) cholesterol, and free fatty acids in the multiple-dose RGE ( $1.5 \mathrm{~g} / \mathrm{kg} / \mathrm{day})$-treated group, indicating that RGE had negligible effects on lipid homeostasis (Table 3). 


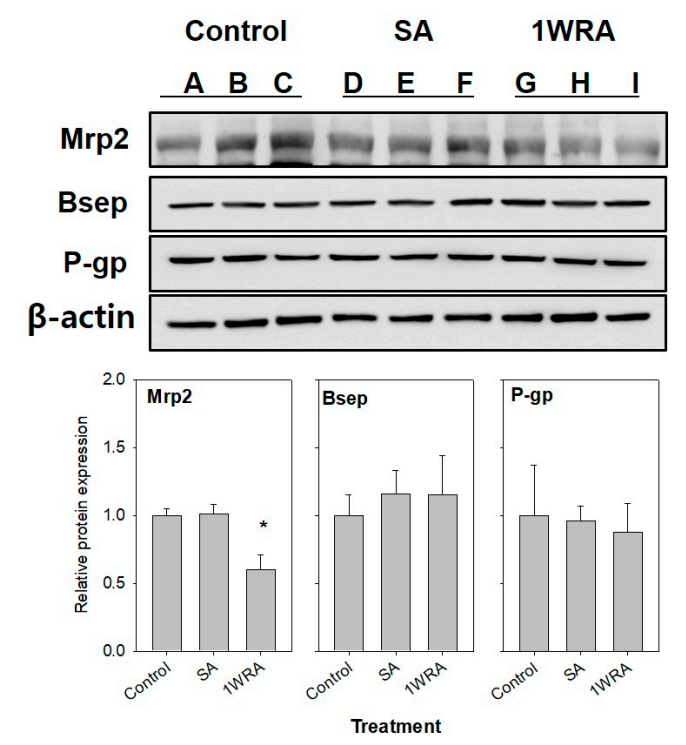

Figure 3. Protein expression of Mrp2 in the liver of rats in the control (lanes A, B, and C), SA (lanes D, E, and F), and 1WRA (lanes G, H, and I) groups. $\beta$-actin served as a loading control. Quantitative analysis of Western blot results is shown in the lower panel. Each bar represents the mean $\pm \mathrm{SD}$ of three independent densitometric analyses. ${ }^{*} p<0.05$, significant compared with SA group by Student's $t$-test.

Table 3. Biochemical parameters from rat plasma following multiple administration of RGE for 1 week at a dose of $1.5 \mathrm{~g} / \mathrm{kg} /$ day.

\begin{tabular}{clcc}
\hline Biochemical Parameters & & Control & 1WRA \\
\hline Alanine aminotransferase (ALT) & Unit/L & $72.7 \pm 13.3$ & $66.3 \pm 28.0$ \\
Aspartate aminotransferase (AST) & Unit/L & $27.3 \pm 3.1$ & $41.0 \pm 29.8$ \\
Triglyceride & $\mathrm{mg} / \mathrm{dL}$ & $80.3 \pm 57.0$ & $73.7 \pm 10.5$ \\
Total cholesterol & $\mathrm{mg} / \mathrm{dL}$ & $62.7 \pm 13.3$ & $53.7 \pm 9.1$ \\
HDL cholesterol & $\mathrm{mg} / \mathrm{dL}$ & $54.7 \pm 9.9$ & $49.0 \pm 1.7$ \\
LDL cholesterol & $\mathrm{mg} / \mathrm{dL}$ & $9.0 \pm 1.0$ & $7.7 \pm 1.2$ \\
Free Fatty acid & $\mathrm{mg} / \mathrm{dL}$ & $161.3 \pm 73.0$ & $166.0 \pm 12.2$ \\
Blood urea nitrogen (BUN) & $\mathrm{mg} / \mathrm{dL}$ & $34.9 \pm 7.2$ & $33.4 \pm 12.1$ \\
Creatinine & $\mathrm{mg} / \mathrm{dL}$ & $0.5 \pm 0.1$ & $0.5 \pm 0.1$ \\
\hline
\end{tabular}

Data are expressed as mean \pm SD from three rats of control and 1WRA groups. HDL: high-density lipoprotein; LDL: low-density lipoprotein.

\subsection{Pharmacokinetics of Methotrexate}

Next, we investigated the effects of RGE on the biliary excretion of Mrp2 substrate drug in rats. Methotrexate was selected as a representative substrate for Mrp2 because $62 \%$ and $27 \%$ of methotrexate intravenous dose is excreted into the bile and urine, respectively, within $3 \mathrm{~h}$ mainly by Mrp2 [31].

Pharmacokinetic parameters of methotrexate related to its excretion were presented in Figure 4 and Table 4. We observed delayed disposition of methotrexate from the plasma (Figure 4), including an increase in $t_{1 / 2}$, in the 1WRA group, which resulted in a significant decrease in the $\mathrm{CL}_{\text {total }}$ and a significant increase in the area under plasma concentration-time curve (AUC) of methotrexate (Table 4).

Since methotrexate underwent the least metabolism [31], disposition from the plasma could be attributed to its excretion via the liver and kidney. Multiple-dose administration of red ginseng decreased the biliary excretion, but not the urinary excretion, of methotrexate (Figure 4B,C) and consequently, $\mathrm{CL}_{\text {bile }}$ of methotrexate decreased; however, its $\mathrm{CL}_{\text {urine }}$ did not change in the 1WRA group (Table 4). $\mathrm{CL}_{\mathrm{bile}}$ accounted for $70 \%$ of the $\mathrm{CL}_{\text {total }}$ of the intravenous bolus injection of methotrexate at a dose of $3 \mathrm{mg} / \mathrm{kg}$ in the control group and $\mathrm{CL}_{\text {urine }}$ accounted for a relatively minor portion 
$(18 \%$, Table 4) in this group. These results showed that biliary excretion is the major pathway of methotrexate elimination, which is consistent with the findings of a previous study [21] and Mrp2 could be a controlling factor in the pharmacokinetics of methotrexate [18]. Therefore, the decrease in the expression of Mrp2 might contribute to the decreased biliary excretion of methotrexate and consequently a 1.5-fold increase in plasma methotrexate exposure (Table 4).

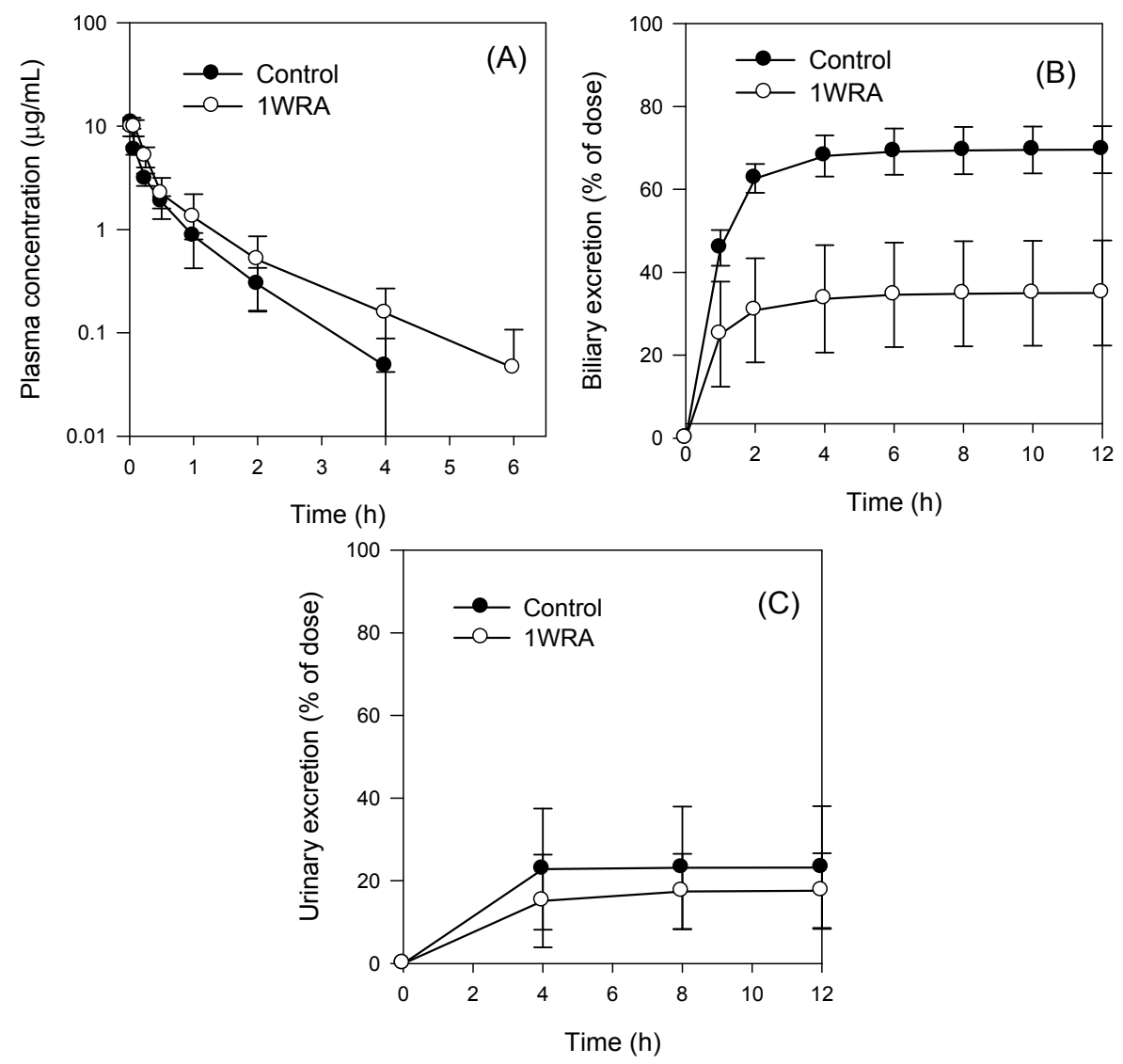

Figure 4. (A) Plasma concentration-time profile, (B) biliary excretion, and (C) urinary excretion of methotrexate following intravenous injection of methotrexate at a dose of $3 \mathrm{mg} / \mathrm{kg}$ in rats from the control and 1WRA groups of RGE (1.5 g/kg, PO). Data represent the means $\pm \operatorname{SD}$ ( $n=3$ or 4 rats /group).

Table 4. Pharmacokinetic parameters of methotrexate following intravenous injection of methotrexate at a dose of $3 \mathrm{mg} / \mathrm{kg}$.

\begin{tabular}{cccc}
\hline \multirow{2}{*}{ Parameters } & \multicolumn{2}{c}{ Groups } \\
\cline { 3 - 4 } & & Control $(\boldsymbol{n = 4 )}$ & 1WRA $(\boldsymbol{n}=\mathbf{6})$ \\
\hline $\mathrm{C}_{0}$ & $\mu \mathrm{g} / \mathrm{mL}$ & $15.6 \pm 2.6$ & $9.7 \pm 1.7^{*}$ \\
$\mathrm{AUC}_{6 \mathrm{~h}}$ & $\mu \mathrm{g} \mathrm{min} / \mathrm{mL}$ & $3.8 \pm 0.2$ & $5.6 \pm 2.2^{*}$ \\
$\mathrm{AUC}_{\infty}$ & $\mu \mathrm{g} \cdot \mathrm{min} / \mathrm{mL}$ & $3.8 \pm 0.2$ & $5.7 \pm 2.3^{*}$ \\
$\mathrm{t}_{1 / 2}$ & $\mathrm{~h}$ & $0.7 \pm 0.2$ & $0.9 \pm 0.2^{*}$ \\
$\mathrm{MRT}$ & $\mathrm{h}$ & $0.7 \pm 0.2$ & $0.9 \pm 0.3$ \\
$\mathrm{~V}_{\mathrm{d}}$ & $\mathrm{mL} / \mathrm{kg}$ & $518.1 \pm 119.0$ & $477.2 \pm 109.3$ \\
$\mathrm{CL}_{\text {total }}$ & $\mathrm{mL} / \mathrm{min} / \mathrm{kg}$ & $13.1 \pm 0.7$ & $9.8 \pm 3.1^{*}$ \\
$\mathrm{CL}_{\text {bile }}$ & $\mathrm{mL} / \mathrm{min} / \mathrm{kg}$ & $9.2 \pm 1.0$ & $4.3 \pm 2.4^{*}$ \\
$\mathrm{CL}_{\text {urine }}$ & $\mathrm{mL} / \mathrm{min} / \mathrm{kg}$ & $2.3 \pm 1.5$ & $1.8 \pm 1.1$ \\
\hline
\end{tabular}

Data are expressed as mean \pm SD from four rats of control and six rats of 1WRA groups. ${ }^{*} p<0.05$, significant compared with SA group by Student's $t$-test. $\mathrm{C}_{0}$ : initial plasma concentration. $\mathrm{AUC}_{6 \mathrm{~h}}$ or $\mathrm{AUC}_{\infty}$ : Area under plasma concentration-time curve from zero to $6 \mathrm{~h}$ or infinity. $\mathrm{t}_{1 / 2}$ : elimination half-life; $\mathrm{Vd}$ : volume of distribution at steady state. MRT: mean residence time; $\mathrm{CL}_{\text {total }}$ : total CL (Dose/plasma AUC). $\mathrm{CL}_{\text {bile }}$ : biliary CL (Excreted amount in bile/plasma AUC). $\mathrm{CL}_{\text {urine: }}$ urinary CL (Excreted amount in urine/plasma AUC). 


\section{Discussion}

RGE treatment at a daily dose of $1.5 \mathrm{~g} / \mathrm{kg}$ for 1 week resulted in steady-state plasma concentrations of major ginsenosides, such as $\mathrm{Rb} 1, \mathrm{Rb} 2, \mathrm{Rc}$, and $\mathrm{Rd}$ (Table 2). In addition, this treatment did not induce biochemical abnormalities in the liver, kidneys, and lipid homeostasis in rats (Table 3). The plasma concentration of $\mathrm{Rb} 1$ was the highest among the ginsenosides detected in rat plasma after oral administration of RGE, followed by Rb2, Rc, and Rd, which was similar to the rank of the ginsenoside content in RGE used in this study (Tables 1 and 2). However, other ginsenosides, such as $\mathrm{Rg} 3, \mathrm{Re}$, and Rh1, were not detected in rat plasma despite their high content in RGE (Tables 1 and 2). Although the underlying mechanisms need to be explored, limited intestinal permeability, short plasma half-life, and intestinal instability owing to the biotransformation and $\mathrm{pH}$-dependent degradation of $\mathrm{Rg} 3$, Re, and Rh1 [32-34], compared to Rb1, Rb2, Rc, and Rd, might contribute to this finding.

Repeated RGE treatment decreased the mRNA and protein expression of Mrp2; however, it did not modulate the expression of Bsep and P-gp in the liver (Figures 2 and 3). Nuclear receptors, such as farnesoid $X$ receptor (FXR, also known as bile acid receptor) and pregnane $X$ receptor (PXR), are known as major regulators of the expression of Bsep and P-gp, respectively [35]. The expression of Mrp2 has been shown to be regulated through transcriptional and post-transcriptional regulation via activation of the Nrf2 and cAMP-dependent protein kinase A (PKA) signaling pathways [5]. Repeated administration of RGE reduced Mrp2 expression; however, the expression of Bsep and P-gp did not change, suggesting that multiple-dose RGE treatment might affect the Nrf2 pathway. This might subsequently contribute to the decrease in Mrp2 mRNA and protein expression, and the increase in the plasma concentration of MTX, an Mrp2 probe substrate drug, by decreasing its elimination and biliary excretion following repeated administration of RGE (Figure 4). Therefore, it could be concluded that multiple-dose administration of RGE could induce herb-drug interactions with various Mrp2 substrate drugs by reducing the hepatobiliary elimination of the Mrp2 substrates, xenobiotics, and their conjugated metabolites, which should be considered when Mrp2 substrate drugs are co-administered with RGE.

In addition, MTX has been used as a chemotherapeutic and immunosuppressive agent for treatment of leukemia, lymphoma, rheumatoid arthritis, and Crohn's disease [24]. In particular, the beneficial effects of red ginseng products for reducing the symptoms of rheumatoid arthritis have been proven in animals and humans [24-27,36]. Therefore, the use of MTX and red ginseng alone or in combination is highly plausible for treatment of rheumatoid arthritis. Repeated high doses of red ginseng could decrease Mrp2 expression, which is crucial for the elimination of MTX. Therefore, in conclusion, this study showed that the herb-drug interactions between red ginseng and MTX occurred via Mrp2 regulation changes in rats, but clinical significance thereof should be determined with follow-up studies.

\section{Materials and Methods}

\subsection{Materials}

Korean red ginseng extract (RGE) was obtained from Punggi Ginseng Cooperative Association (Punggi, Korea). Methotrexate was purchased from Sigma-Aldrich (St. Louis, MO, USA). Analytical standard ginsenosides were purchased from Ambo Institute (Daejeon, Korea).

\subsection{Animals}

Male Sprague-Dawley rats (7-8 weeks, 220-250 g) were purchased from Samtako Co. (Osan, Korea). All animal procedures were approved by the Animal Care and Use Committee of Kyungpook National University (Approval No. 2017-0021) and carried out in accordance with the National Institutes of Health guidance for the care and the use of laboratory animals. 


\subsection{RGE Administration}

Rats in the control group received water $(2 \mathrm{~mL} / \mathrm{kg}$ as a vehicle treatment $)$ orally at 9 a.m. for 7 days by oral gavage. RGE suspension $(1.5 \mathrm{~g} / \mathrm{kg} /$ day, $2 \mathrm{~mL} / \mathrm{kg}$ suspended in water) was administered to rats by oral gavage at 9 a.m. once (SA group), for 7 days (1WRA group), and 14 days (2WRA group), respectively. Two hours after the last treatment of RGE, abdominal arterial blood (about $5 \mathrm{~mL}$ ) and liver tissues were collected from rats in all groups. The liver tissues were snap-frozen for analysis of the mRNA and protein expression of efflux transporters. The plasma samples were used for measurement of plasma ginsenoside concentrations and biochemical parameters. The biochemical parameters such as ALT, AST, triglycerides, plasma cholesterol levels, free fatty acids, blood urea nitrogen and serum creatinine were measured from the service of Seoul Clinical Laboratories (Yongin, Korea) using UV spectrophotometric assay kits from Young-Dong Diagnostics Co. (Yongin, Korea). Lyphocheck assayed chemistry control (normal and abnormal standards; Bio-Rad, Hercules, CA, USA) were used as positive control and YD calibrator (Young-Dong Diagnostics Co.) was used for external calibration.

\subsection{Bioanalysis of 14 Ginsenosides}

Ginsenoside concentrations in RGE and plasma samples were analyzed using an Agilent 6470 triple quadrupole liquid chromatography-tandem mass spectrometry (LC-MS/MS) system (Agilent, Wilmington, DE, USA) equipped with an Agilent 1260 high-performance liquid chromatography (HPLC) system according to the previously published method [23]. Briefly, diluted RGE samples $(50 \mu \mathrm{L})$ and plasma samples $(50 \mu \mathrm{L})$ were protein-precipitated with methanol $200 \mu \mathrm{L}$ containing berberine $(0.5 \mathrm{ng} / \mathrm{mL}$; used as an internal standard $)$. Aliquots $(10 \mu \mathrm{L})$ of the supernatant were injected into the LC-MS/MS system for the analysis of ginsenosides. Ginsenosides were separated on a Synergi Polar RP column $(2 \times 150 \mathrm{~mm}, 4 \mu \mathrm{m}$ particle size; Phenomenex $)$ using a mobile phase consisting of water (A) and methanol (B) containing $0.1 \%$ formic acid at a flow rate of $0.3 \mathrm{~mL} / \mathrm{min}$. The solvent gradient program was as follows: (1) 0-1 $\mathrm{min}, 70 \% \mathrm{~B}$; (2) 1-6.5 min, $90 \% \mathrm{~B}$; (3) 6.5-7 $\mathrm{min}, 80 \% \mathrm{~B}$; and (4) 7-14 $\mathrm{min}, 70 \% \mathrm{~B}$.

Quantification of a separated ginsenoside peak was performed using MRM mode at $\mathrm{m} / \mathrm{z}$ $1131.6 \rightarrow 365.1$ for $\mathrm{Rb} 1$ (retention time $(\mathrm{rt})=4.1 \mathrm{~min}), \mathrm{m} / z 1101.6 \rightarrow 335.1$ for $\mathrm{Rb} 2(\mathrm{rt}=5.0 \mathrm{~min})$ and $\operatorname{Rc}(\mathrm{rt}=4.2 \mathrm{~min}), \mathrm{m} / z 969.9 \rightarrow 789.5$ for $\operatorname{Rd}(\mathrm{rt}=5.1 \mathrm{~min})$ and $\operatorname{Re}(\mathrm{rt}=1.8 \mathrm{~min}), \mathrm{m} / z 823.5 \rightarrow 365.1$ for $\operatorname{Rf}(\mathrm{rt}=2.7 \mathrm{~min}), m / z 824 \rightarrow 643.6$ for $\operatorname{Rg} 1\left(\mathrm{~T}_{\mathrm{R}}=1.9 \mathrm{~min}\right), m / z 807.5 \rightarrow 365.1$ for $\operatorname{Rg} 3\left(\mathrm{~T}_{\mathrm{R}}=6.0 \mathrm{~min}\right)$, $m / z 661.5 \rightarrow 203.1$ for Rh1 (rt = 3.2 $\mathrm{min}), m / z 645.5 \rightarrow 645.5$ for $\operatorname{Rh} 2(\mathrm{rt}=6.9 \mathrm{~min}), \mathrm{m} / z 661.5 \rightarrow 203.1$ for F1 ( $\mathrm{rt}=3.7 \mathrm{~min}), m / z 807.5 \rightarrow 627.5$ for F2 ( $\mathrm{rt}=6.1 \mathrm{~min}), m / z 645.5 \rightarrow 203.1$ for compound $\mathrm{K}(\mathrm{rt}=6.8 \mathrm{~min}), \mathrm{m} / \mathrm{z} 483.4 \rightarrow 483.4$ for protopanaxadiol $(\mathrm{rt}=6.8 \mathrm{~min}), \mathrm{m} / z 499.4 \rightarrow 499.4$ for protopanaxatriol $(\mathrm{rt}=6.8 \mathrm{~min})$, and $\mathrm{m} / \mathrm{z} 336.1 \rightarrow 320$ for berberine (internal standard, IS) $(\mathrm{rt}=3.7 \mathrm{~min}$ ) in the positive ionization mode with collision energy (CE) of 30-65 eV.

\subsection{Real-Time Reverse-Transcription Polymerase Chain Reaction (RT-PCR) Analysis}

Total RNA was extracted from liver samples (100 mg) using Qiazol (Qiagen, Valencia, CA, USA), according to the vendor's protocol. The concentration of total RNA was determined by Nano Vue Plus (GE healthcare Korea, Seoul, Korea).

RT-PCR of Mrp1, Mrp2, Bsep, and P-gp was performed using a LightCycler 96 real-time PCR system (Roche, Carlsbad, CA, USA) as previously described [21,37]. Primers were designed using ProbeFinder as follows: $5^{\prime}$-tgagggtggagaaaaggttg-5' and $5^{\prime}$-aaacccagggtgagagatga- $3^{\prime}$ for Mrp1 (NM_022281.2); 5'-aatacatgaccttttggtgtttctg-5' and 5'-acgaaaccgatcagcaactt-3' for Mrp2 (NM_012833.2); 5'-gggcagtcacacccatctac-5' and 5'-ctttatcgaggagtgaaaaagtcc-3' for Bsep (NM_031760.1); $5^{\prime}$-cacagaccgtcagcgaca-5' and $5^{\prime}$-caatgcccgtgtaatagtaggc-3' for P-gp (NM_012623.2). 


\subsection{Western Blot Analysis}

Protein expression of Mrp2, Bsep, and P-gp was measured as previously described [21]. Briefly, total protein was obtained by homogenizing $100 \mathrm{mg}$ of liver samples with equal volume of a tissue lysis buffer. Protein samples (30-50 $\mu \mathrm{g}$ ) were loaded and separated by sodium dodecyl sulfate-polyacrylamide gel electrophoresis (SDS-PAGE) on a 4-15\% gradient gel (Bio-Rad). Separated proteins were transferred onto a Potran $0.45 \mu \mathrm{m}$ nitrocellulose membrane (GE Healthcare). The membrane was blocked with $5 \%$ bovine serum albumin in Tris-buffered saline containing $0.1 \%$ Tween20 (TBST) (Biosesang, Seoul, Republic of Korea) for $1 \mathrm{~h}$ and incubated with primary antibody at $4{ }^{\circ} \mathrm{C}$ for $12 \mathrm{~h}$. Primary antibodies were used as follows: anti-Mrp2 antibody (ab203397, dilution 1:1000, Abcam, San Francisco, CA, USA), anti-Bsep antibody (ab217532, dilution 1:1000, Abcam), anti-P-gp antibody (E1Y7S, dilution 1:1000, Cell signaling technology, Danvers, MA, USA) and beta-actin antibody (1:1000, Cell signaling technology). The membrane was rinsed twice with TBST at $25^{\circ} \mathrm{C}$ and treated with horseradish peroxidase-labeled anti-rabbit IgG antibody (Santa Cruz Biotechnology, Dallas, TX, USA). Protein bands were visualized using a Luminata Forte enhanced chemiluminescence system (Millipore, Burlington, MA, USA), and beta-actin served as the loading control.

\subsection{Pharmacokinetics of Methotrexate}

Pharmacokinetic study of methotrexate was performed as previously described [21]. Briefly, the femoral arteries, femoral veins, and bile duct of rats in the control and 1WRA groups were cannulated with PE50 or PE10 polyethylene tubing (Jungdo, Seoul, Korea) under anesthesia. Pharmacokinetic studies started $2 \mathrm{~h}$ after the last RGE treatment.

Methotrexate solution ( $3 \mathrm{mg} / \mathrm{kg}$ in phosphate-buffered saline) was injected intravenously to rats. Blood samples (about $150 \mu \mathrm{L}$ ) were collected from the femoral artery at $0,0.03,0.08,0.25,0.5,1,2$, 4 , and $6 \mathrm{~h}$ after the methotrexate injection. Bile samples were collected at 1 and $2 \mathrm{~h}$ and every $2 \mathrm{~h}$ up to $12 \mathrm{~h}$ through the bile cannula. Urine samples were also collected every $4 \mathrm{~h}$ up to $12 \mathrm{~h}$ through urinary bladder.

Aliquots $(50 \mu \mathrm{L})$ of plasma, bile, and urine samples were added to $250 \mu \mathrm{L}$ of acetonitrile containing $2 \mathrm{ng} / \mathrm{mL}$ of propranolol (IS). After vortexing for $10 \mathrm{~min}$ and centrifugation at 10,000 $\mathrm{g}$ for $10 \mathrm{~min}$, an aliquot $(1 \mu \mathrm{L})$ of the supernatant was injected directly into the Agilent 6430 triple quadrupole LC-MS/MS system, according to the previously described method [21]. Briefly, methotrexate and propranolol (IS) were eluted at 2.1 and $2.7 \mathrm{~min}$, respectively, on a Synergi Polar RP column. Mobile phase consisted of water $(0.1 \%$ formic acid):acetonitrile $(0.1 \%$ formic acid $)=20: 80(v / v)$ and eluted at a rate of $0.25 \mathrm{~mL} / \mathrm{min}$. Quantitation was carried out at $m / z 455.2 \rightarrow 308.1$ for methotrexate and $m / z 260 \rightarrow 116$ for IS in the positive ionization mode.

\subsection{Data Analysis}

Pharmacokinetic parameters were calculated by non-compartmental analysis using WinNonlin version 2.0 software (Pharsight, Certara, NJ, USA).

Statistical comparisons were performed by $t$-test using the Statistical Package for the Social Sciences (SPSS Inc., Chicago, IL, USA). A $p$ value $<0.05$ was considered statistically significant.

Author Contributions: Conceptualization, M.-K.C. and I.-S.S.; methodology, investigation, and data interpretation, S.L., M.K., M.-K.C., and I.-S.S.; writing-original draft preparation, S.L.; writing-review and editing and supervision, M.-K.C. and I.-S.S.; funding acquisition, I.-S.S.

Acknowledgments: This research was funded by a grant of the Korea Institute of Planning and Evaluation for Technology in Food, Agriculture, Forestry and Fisheries (IPET) through Export Promotion Technology Development Program, funded by Ministry of Agriculture, Food and Rural Affairs (MAFRA) (No. 316017-3).

Conflicts of Interest: The authors declare no conflict of interest. 


\section{References}

1. Ru, W.; Wang, D.; Xu, Y.; He, X.; Sun, Y.E.; Qian, L.; Zhou, X.; Qin, Y. Chemical constituents and bioactivities of panax ginseng (c. A. Mey.). Drug Discov. Ther. 2015, 9, 23-32. [CrossRef] [PubMed]

2. Lee, C.H.; Kim, J.H. A review on the medicinal potentials of ginseng and ginsenosides on cardiovascular diseases. J. Ginseng Res. 2014, 38, 161-166. [CrossRef] [PubMed]

3. Lee, S.M.; Bae, B.S.; Park, H.W.; Ahn, N.G.; Cho, B.G.; Cho, Y.L.; Kwak, Y.S. Characterization of korean red ginseng (panax ginseng meyer): History, preparation method, and chemical composition. J. Ginseng Res. 2015, 39, 384-391. [CrossRef] [PubMed]

4. Kim, J.H.; Yi, Y.S.; Kim, M.Y.; Cho, J.Y. Role of ginsenosides, the main active components of panax ginseng, in inflammatory responses and diseases. J. Ginseng Res. 2017, 41, 435-443. [CrossRef] [PubMed]

5. Yun, T.K.; Choi, S.Y.; Yun, H.Y. Epidemiological study on cancer prevention by ginseng: Are all kinds of cancers preventable by ginseng? J. Korean Med. Sci. 2001, 16, 192S-197S. [CrossRef] [PubMed]

6. Gui, Q.F.; Xu, Z.R.; Xu, K.Y.; Yang, Y.M. The efficacy of ginseng-related therapies in type 2 diabetes mellitus: An updated systematic review and meta-analysis. Medicine 2016, 95, e2584. [CrossRef] [PubMed]

7. Park, T.Y.; Hong, M.; Sung, H.; Kim, S.; Suk, K.T. Effect of korean red ginseng in chronic liver disease. J. Ginseng Res. 2017, 41, 450-455. [CrossRef] [PubMed]

8. Ji, H.Y.; Liu, K.H.; Kong, T.Y.; Jeong, H.U.; Choi, S.Z.; Son, M.; Cho, Y.Y.; Lee, H.S. Evaluation of da-9801, a new herbal drug for diabetic neuropathy, on metabolism-mediated interaction. Arch. Pharm. Res. 2013, 36, 1-5. [CrossRef] [PubMed]

9. Gurley, B.J.; Gardner, S.F.; Hubbard, M.A.; Williams, D.K.; Gentry, W.B.; Cui, Y.; Ang, C.Y. Clinical assessment of effects of botanical supplementation on cytochrome p450 phenotypes in the elderly: St john's wort, garlic oil, panax ginseng and ginkgo biloba. Drugs Aging 2005, 22, 525-539. [CrossRef] [PubMed]

10. Kim, D.S.; Kim, Y.; Jeon, J.Y.; Kim, M.G. Effect of red ginseng on cytochrome p450 and p-glycoprotein activities in healthy volunteers. J. Ginseng Res. 2016, 40, 375-381. [CrossRef] [PubMed]

11. Fasinu, P.S.; Bouic, P.J.; Rosenkranz, B. An overview of the evidence and mechanisms of herb-drug interactions. Front. Pharmacol. 2012, 3, 69. [CrossRef] [PubMed]

12. Chen, X.W.; Serag, E.S.; Sneed, K.B.; Liang, J.; Chew, H.; Pan, S.Y.; Zhou, S.F. Clinical herbal interactions with conventional drugs: From molecules to maladies. Curr. Med. Chem. 2011, 18, 4836-4850. [CrossRef] [PubMed]

13. Chen, X.W.; Sneed, K.B.; Pan, S.Y.; Cao, C.; Kanwar, J.R.; Chew, H.; Zhou, S.F. Herb-drug interactions and mechanistic and clinical considerations. Curr. Drug Metab. 2012, 13, 640-651. [CrossRef] [PubMed]

14. Leslie, E.M.; Deeley, R.G.; Cole, S.P. Multidrug resistance proteins: Role of p-glycoprotein, mrp1, mrp2, and bcrp (abcg2) in tissue defense. Toxicol. Appl. Pharmacol. 2005, 204, 216-237. [CrossRef] [PubMed]

15. Rappa, G.; Finch, R.A.; Sartorelli, A.C.; Lorico, A. New insights into the biology and pharmacology of the multidrug resistance protein (mrp) from gene knockout models. Biochem. Pharmacol. 1999, 58, 557-562. [PubMed]

16. Lorico, A.; Rappa, G.; Finch, R.A.; Yang, D.; Flavell, R.A.; Sartorelli, A.C. Disruption of the murine mrp (multidrug resistance protein) gene leads to increased sensitivity to etoposide (vp-16) and increased levels of glutathione. Cancer Res. 1997, 57, 5238-5242. [PubMed]

17. Dietrich, C.G.; Geier, A.; Oude Elferink, R.P. Abc of oral bioavailability: Transporters as gatekeepers in the gut. Gut 2003, 52, 1788-1795. [CrossRef] [PubMed]

18. Oude Elferink, R.P.; Meijer, D.K.; Kuipers, F.; Jansen, P.L.; Groen, A.K.; Groothuis, G.M. Hepatobiliary secretion of organic compounds; molecular mechanisms of membrane transport. Biochim. Biophys. Acta 1995, 1241, 215-268. [CrossRef]

19. Evers, R.; de Haas, M.; Sparidans, R.; Beijnen, J.; Wielinga, P.R.; Lankelma, J.; Borst, P. Vinblastine and sulfinpyrazone export by the multidrug resistance protein mrp2 is associated with glutathione export. Br. J. Cancer 2000, 83, 375-383. [CrossRef] [PubMed]

20. Suzuki, T.; Nishio, K.; Tanabe, S. The mrp family and anticancer drug metabolism. Curr. Drug Metab. 2001, 2, 367-377. [CrossRef] [PubMed]

21. Kim, M.J.; Kang, Y.J.; Kwon, M.; Choi, Y.A.; Choi, M.K.; Chi, H.Y.; Yoo, H.H.; Shim, C.K.; Song, I.S. Ursodeoxycholate restores biliary excretion of methotrexate in rats with ethinyl estradiol induced-cholestasis by restoring canalicular mrp2 expression. Int. J. Mol. Sci. 2018, 19, 1120. [CrossRef] [PubMed] 
22. Park, S.H.; Jang, J.H.; Chen, C.Y.; Na, H.K.; Surh, Y.J. A formulated red ginseng extract rescues pc12 cells from pcb-induced oxidative cell death through nrf2-mediated upregulation of heme oxygenase-1 and glutamate cysteine ligase. Toxicology 2010, 278, 131-139. [CrossRef] [PubMed]

23. Seong, S.J.; Kang, W.Y.; Heo, J.K.; Jo, J.; Choi, W.G.; Liu, K.H.; Lee, S.; Choi, M.K.; Han, Y.H.; Lee, H.S.; et al. A comprehensive in vivo and in vitro assessment of the drug interaction potential of red ginseng. Clin. Ther. 2018, 40, 1322-1337. [CrossRef] [PubMed]

24. Endale, M.; Im, E.J.; Lee, J.Y.; Kim, S.D.; Yayeh, T.; Song, Y.B.; Kwak, Y.S.; Kim, C.; Kim, S.H.; Roh, S.S.; et al. Korean red ginseng saponin fraction rich in ginsenoside-rb1, rc and rb2 attenuates the severity of mouse collagen-induced arthritis. Mediat. Inflamm. 2014, 2014, 748964. [CrossRef] [PubMed]

25. Cho, S.K.; Kim, D.; Yoo, D.; Jang, E.J.; Jun, J.B.; Sung, Y.K. Korean red ginseng exhibits no significant adverse effect on disease activity in patients with rheumatoid arthritis: A randomized, double-blind, crossover study. J. Ginseng Res. 2018, 42, 144-148. [CrossRef] [PubMed]

26. Yu, T.; Rhee, M.H.; Lee, J.; Kim, S.H.; Yang, Y.; Kim, H.G.; Kim, Y.; Kim, C.; Kwak, Y.S.; Kim, J.H.; et al. Ginsenoside rc from korean red ginseng (panax ginseng c.A. Meyer) attenuates inflammatory symptoms of gastritis, hepatitis and arthritis. Am. J. Chin. Med. 2016, 44, 595-615. [CrossRef] [PubMed]

27. Jhun, J.; Lee, J.; Byun, J.K.; Kim, E.K.; Woo, J.W.; Lee, J.H.; Kwok, S.K.; Ju, J.H.; Park, K.S.; Kim, H.Y.; et al. Red ginseng extract ameliorates autoimmune arthritis via regulation of stat 3 pathway, th17/treg balance, and osteoclastogenesis in mice and human. Mediat. Inflamm. 2014, 2014, 351856. [CrossRef] [PubMed]

28. Kim, H.K. Pharmacokinetics of ginsenoside rb1 and its metabolite compound $\mathrm{k}$ after oral administration of korean red ginseng extract. J. Ginseng Res. 2013, 37, 451-456. [CrossRef] [PubMed]

29. Xu, Q.F.; Fang, X.L.; Chen, D.F. Pharmacokinetics and bioavailability of ginsenoside rb1 and rg1 from panax notoginseng in rats. J. Ethnopharmacol. 2003, 84, 187-192. [CrossRef]

30. Leung, K.W.; Wong, A.S. Pharmacology of ginsenosides: A literature review. Chin. Med. 2010, 5, 20. [CrossRef] [PubMed]

31. Masuda, M.; I'Izuka, Y.; Yamazaki, M.; Nishigaki, R.; Kato, Y.; Ni'inuma, K.; Suzuki, H.; Sugiyama, Y. Methotrexate is excreted into the bile by canalicular multispecific organic anion transporter in rats. Cancer Res. 1997, 57, 3506-3510. [PubMed]

32. Liu, H.; Yang, J.; Du, F.; Gao, X.; Ma, X.; Huang, Y.; Xu, F.; Niu, W.; Wang, F.; Mao, Y.; et al. Absorption and disposition of ginsenosides after oral administration of panax notoginseng extract to rats. Drug Metab. Dispos. 2009, 37, 2290-2298. [CrossRef] [PubMed]

33. Zheng, M.M.; Xu, F.X.; Li, Y.J.; Xi, X.Z.; Cui, X.W.; Han, C.C.; Zhang, X.L. Study on transformation of ginsenosides in different methods. Biomed. Res. Int. 2017, 2017, 8601027. [CrossRef] [PubMed]

34. Miyamoto, E.; Odashima, S.; Kitagawa, I.; Tsuji, A. Stability kinetics of ginsenosides in aqueous solution. J. Pharm. Sci. 1984, 73, 409-410. [CrossRef] [PubMed]

35. Ott, M.; Fricker, G.; Bauer, B. Pregnane x receptor (pxr) regulates p-glycoprotein at the blood-brain barrier: Functional similarities between pig and human pxr. J. Pharmacol. Exp. Ther. 2009, 329, 141-149. [CrossRef] [PubMed]

36. Kim, K.R.; Chung, T.Y.; Shin, H.; Son, S.H.; Park, K.K.; Choi, J.H.; Chung, W.Y. Red ginseng saponin extract attenuates murine collagen-induced arthritis by reducing pro-inflammatory responses and matrix metalloproteinase-3 expression. Biol. Pharm. Bull. 2010, 33, 604-610. [CrossRef] [PubMed]

37. Xu, H.; Bionaz, M.; Sloboda, D.M.; Ehrlich, L.; Li, S.; Newnham, J.P.; Dudenhausen, J.W.; Henrich, W.; Plagemann, A.; Challis, J.R.; et al. The dilution effect and the importance of selecting the right internal control genes for rt-qpcr: A paradigmatic approach in fetal sheep. BMC Res. Notes 2015, 8, 58. [CrossRef] [PubMed]

Sample Availability: Red ginseng extract are available from the authors. 